\title{
TWO KEY VOLATILES OF CHINESE WHITE PINE (PINUS ARMANDII) (PINALES: PINACEAE: PINOIDEAE) PHLOEM RESIST INVASION BY CHINESE WHITE PINE BEETLE (DENDROCTONUS ARMANDII) (COLEOPTERA: CURCULIONIDAE: SCOLYTINAE)
}

\author{
ZHAO, M. ${ }^{1,2}-$ KANG, $X .^{3}-$ AN, $H^{1}{ }^{1}-$ LIU, B. ${ }^{3}-$ CHEN, H. ${ }^{1 *}$ \\ ${ }^{1}$ State Key Laboratory for Conservation and Utilization of Subtropical Agro-Bioresources \\ (South China Agricultural University), Guangdong Key Laboratory for Innovative Development \\ and Utilization of Forest Plant Germplasm, College of Forestry and Landscape Architecture, \\ South China Agricultural University, Guangzhou 510642, Guangdong, China \\ ${ }^{2}$ Key Lab Vector Biol \& Pathogen Control Zhejiang P, College of Life Science, Huzhou \\ University, Huzhou, Zhejiang 313000, China \\ ${ }^{3}$ College of Forestry, Northwest A\&F University, Yangling, Shaanxi 712100, China \\ *Corresponding author \\ e-mail: chenhuiyl@163.com; phone:+86-20-8528-0256; fax: +86-20-8528-0256
}

(Received 20 $0^{\text {th }}$ Mar 2021; accepted $6^{\text {th }}$ Dec 2021)

\begin{abstract}
Pinus armandii phloem is the key tissue in which Dendroctonus armandii live and breed. Although previous research examined the volatiles in $P$. armandii phloem, the dynamic changes and functions of these volatiles were never revealed. This study detected the changes in $P$. armandii phloem volatiles at each stage of infestation from healthy to dead trees and tested the toxicity of these volatiles against $D$. armandii. It revealed that (1) the weight of females was significantly greater than that of males, and females were more tolerant to host volatiles than males. (2) Limonene and myrtanol of $P$. armandii phloem volatiles played the key roles in resisting the invasion of $D$. armandii. The first increased the percentage of limonene together with other volatiles killing $D$. armandii in the resistant period of $P$. armandii, and the second synthesised myrtanol to further resist the invasion of $D$. armandii in the retreat period of $P$. armandii. These observations highlight the differences in the resistance of males and females to toxicity from the volatiles and the difference in the toxicity of different volatiles to $D$. armandii, revealing the defensive system of $P$. armandii phloem to provide a theoretical basis for the control and management of $D$. armandii.
\end{abstract}

Keywords: host volatiles, toxicity, host defence, limonene, myrtanol

\section{Introduction}

The Chinese white pine beetle (Dendroctonus armandii) is the most destructive forest pest in the Qinling Mountains and Ta-pa Mountains of China (Chen et al., 2010). Unlike red turpentine beetle (Dendroctonus valens) and mountain pine beetle (Dendroctonus ponderosae) that invade weakened pine trees, and only infest healthy trees during outbreaks (Sun et al., 2013; Krause et al., 2018), D. armandii is a primary pest of healthy Chinese white pine (Pinus armandii) (Hu et al., 2016). D. armandii has two generations per year at elevations lower than $1700 \mathrm{~m}$ a.s.l, three generations in two years between 1700 and $2150 \mathrm{~m}$ a.s.l, and one generation per year in areas higher than $2150 \mathrm{~m}$ a.s.1 (Ning et al., 2019). Females invade first and overcome the tree's resistance, drill tunnels, and release pheromones to attract males (Dai et al., 2015). The successful invasion of $D$. armandii is often followed by colonization of secondary pests (such as Ips acuminatus, 
Ips sexdentatus, Hylurgops longipilis, Tomicus piniperda and Trypodendron lineatum) in the weakened pines, and the infected $P$. armandii will die in two years (Chen et al., 2007). Since 1970 , more than $3 \times 10^{8} \mathrm{~m}^{3}$ of $P$. armandii trees (older than 30 years) have been harmed by $D$. armandii (Xie and Lv, 2012), and even young $P$. armandii trees were found to have been invaded by $D$. armandii (Chen et al., 2015).

Insect pheromones play a vital role in the management of bark beetles (Pureswaran et al., 2008; Perkins et al., 2015; Gillette et al., 2009). Integrated pest management measures focused on the identification of pheromones have been performed for $D$. armandii in recent years. Aggregation pheromones are considered to be a key factor in the success of insect invasion and colonization (Faccoli and Stergulc, 2008; Blazenec and Jakus, 2009). Frontalin $+\alpha$-pinene is an aggregation pheromone released by virgin females and mated males of $D$. armandii (Zhao et al., 2017a), and myrtenal may be an aggregation pheromone produced by females of $D$. armandii to exert aggregation effects on other females (Zhao et al., 2019). The anti-aggregation pheromones of bark beetles, such as verbenone in $D$. ponderosae and $D$. valens, and toxic host terpene have been used to protect pine species from bark beetles (Gillette et al., 2006). Verbenone has been detected using gas chromatography and mass spectrometry (GC-MS) analyses of the hindguts of female beetles and the fumes emanating from $P$. armandii logs naturally attacked by $D$. armandii (Xie and Lv, 2012; Chen et al., 2015). In our previous study, verbenone was verified as an anti-aggregation pheromone based on electrophysiological (EAG) and Ytube laboratory assays. In addition, field trials indicated that the addition of verbenone to the bait used to trap $D$. armandii significantly decreased the efficiency of field trapping (Zhao et al., 2017b). trans-Verbenol is a pheromone of western pine beetle (Dendroctonus brevicomis), southern pine beetle (Dendroctonus frontalis), D. ponderosae and Douglas-fir beetle (Dendroctonus pseudotsugae) (Byers et al., 1984; Chiu et al., 2018; Pureswaran et al., 2004), but it has not been found to have a clear role in the pheromone ecology of $D$. armandii (Zhao et al., 2017b). Quantities of potential semiochemicals identified in extracts of the hindguts of female D. armandii, include cisverbenol, trans-verbenol, $\alpha$-pinene, $\beta$-caryophyllene, 3 -carene, verbenone, myrcene and limonene (Xie and Lv, 2012).

Leptographium qinlingensis is a symbiotic fungi of $D$. armandii that assists in the invasion of the host tree by blocking flow of water and resin, thereby reducing host defenses. Metabolites biosynthesized by $L$. qinlingensis that may be phytotoxic to $P$. armandii seedlings, include 6-methoxymethyleugenin, maculosin and cerevisterol (Li et al., 2012).

Some volatiles of $P$. armandii were tested and applied to traps in the field. Myrtenol was found to be a kind of $P$. armandii volatile and did not exhibit significant toxicity towards D. armandii (Zhao et al., 2019). Myrtanol was produced by infected $P$. armandii after $D$. armandii invasion and had significant toxicity towards $D$. armandii, especially females (Zhao et al., 2019). $\alpha$-Pinene, camphene, $\beta$-pinene, myrcene, 3carene, limonene and longifolene were detected from $P$. armandii logs with or without D. armandii attack (Chen et al., 2015).

The pine defence against bark beetles is multifaceted and temporally dynamic (Franceschi et al., 2005). Resin flow can kill invading bark beetles (Strom et al., 2002; Hood and Sala, 2015; Kane and Kolb, 2010). In addition, pines produce defence volatiles, such as monoterpenes, sesquiterpenes, diterpenes, and phenolics (Raffa et al., 2017), and the invasion of bark beetles can increase the concentration of host phloem volatiles (Kolb et al., 2019). Other defence measures include the physical defence 
provided by bark and water (Arango-Velez et al., 2016; Erbilgin et al., 2017; Kolb et al., 2019). Resin flow and terpene release are known means of defence in response to bark beetles and their symbiotic fungi (Arango-Velez et al., 2018; Roth et al., 2018). For example, ponderosa pine can undergo induction of both resin flow and phloem terpenes in response to bark beetle attack (Kolb et al., 2019). Current research has mainly concentrated on $P$. armandii trees in a single state, such as a healthy or infested tree. The kinds of volatiles produced during different stages of host condition from fully healthy to fully infested is not clear. Whether new volatiles are synthesized specifically to resist insect invasion is also unknown. There has been no study on the dynamic changes of volatiles during the whole process of $P$. armandii resistance to bark beetle invasion. The purpose of this study was to examine the changes in host volatile production during the invasion process of $P$. armandii from healthy to dead and to test the toxicity of these volatiles against $D$. armandii to obtain more specific knowledge of the autonomic chemical defence process of $P$. armandii.

\section{Materials and methods}

\section{Sampling}

The study sites were located on the southern slope of the middle Qinling Mountains, Ningshan County, Shaanxi, China, and mainly occurred in Huoditang Forest Farm $\left(33^{\circ} 18^{\prime}-33^{\circ} 28^{\prime} \mathrm{N}, 108^{\circ} 21^{\prime}-108^{\circ} 39^{\prime} \mathrm{E}\right)$ and Pingheliang Forest Farm $\left(33^{\circ} 22^{\prime}-33^{\circ} 34^{\prime} \mathrm{N}\right.$, $\left.108^{\circ} 24^{\prime}-108^{\circ} 36^{\prime} \mathrm{E}\right)$. The two forest farms were chosen because they were severely affected by $D$. armandii. The investigated $P$. armandii trees were distributed widely inside the two areas.

For convenience, the defence process of $P$. armandii against invasion by $D$. armandii was divided into four periods: healthy period, resistance period, retreat period and withered period. Healthy period was defined by the lack of resinous pitch tubes in $P$. armandii trunks. The resistance period was defined by resinous pitch tubes in $P$. armandii trunks; resinous pitch tubes are comprised of colloidal liquid containing some dead $D$. armandii. Dry frass is usually a sign of successful invasion by bark beetles (Gillette et al., 2006). The retreat period was defined by a change in the resinous pitch tubes to dry frass, and a change in the needles from green to yellow. The withered period was defined by $D$. armandii mating and production of the next generation, the needles becoming withered and yellow, and some limbs dropping out of the trees.

Phloem samples were collected from $P$. armandii trunks with a small sickle (length $\times$ width $=22 \mathrm{~cm} \times 6 \mathrm{~cm}$, custom-made by a blacksmith) in June 2019. Phloem was collected from healthy $P$. armandii and infested areas of different period (resistance, retreat and withered periods) of attacked trees, and the beetles and frass were cleared from the infested phloem. These phloem samples of every period were collected from five different trees of the period subjected to five repetitions. Glass culture dishes with phloem samples were placed in an outdoor cooler $\left(4^{\circ} \mathrm{C}\right)$ and transported to the laboratory.

\section{Collection and identification of host volatiles}

We collected five $1.5 \mathrm{~g}$ samples of phloem from each of the four periods and placed each sample in a separate $50 \mathrm{ml}$ vial for volatile collection. The volatiles released from these phloem samples were collected passively by headspace solid-phase microextraction (HS-SPME) (Chai et al., 2012; Keenan et al., 2012). An SPME fibre 
coated with a 75- $\mu \mathrm{m}$ film of divinylbenzene/carboxen/polydimethylsiloxane (DVB/CAR/PDMS) (Supelco, Sigma-Aldrich, Bellefonte, PA, USA) was exposed to the headspace of each vial/phloem sample for $3 \mathrm{~min}$. The split ratio of the phloem samples was 10:1. The fibre was selected due to its suitability for gases and compounds with a low molecular mass. Prior to use, the fibre was preconditioned in the injection port of the gas chromatograph at $270{ }^{\circ} \mathrm{C}$ for $60 \mathrm{~min}$. Extracts were analysed using a DB$5 \mathrm{MS}$ column $(30 \mathrm{~m} \times 0.25 \mathrm{~mm} \times 0.25 \mu \mathrm{m})$ (Thermo Fisher Scientific Company, Shanghai, China). The SPME fibre was injected directly into the injection port at a temperature of $250{ }^{\circ} \mathrm{C}$ for $3 \mathrm{~min}$. The temperature of the $\mathrm{GC}$ oven was maintained at $40{ }^{\circ} \mathrm{C}$ for $2.5 \mathrm{~min}$, increased to $240{ }^{\circ} \mathrm{C}$ at a rate of $6{ }^{\circ} \mathrm{C} / \mathrm{min}$ and maintained at $240{ }^{\circ} \mathrm{C}$ for $10 \mathrm{~min}$. The flow of helium (carrier gas) was $1.0 \mathrm{~mL} / \mathrm{min}$. Compounds were identified by comparison of their retention times and mass spectra with those in the NIST and Varian libraries. Furthermore, the retention times and mass spectra of $\alpha$-pinene, $\beta$ pinene, myrcene, limonene, 3-carene and longifolene detected during the GC-MS analysis were also compared with the purchased standards.

\section{Insects}

$P$. armandii $\operatorname{logs}$ invaded by $D$. armandii larvae and pupae were felled in the Pingheliang Forest Farm $\left(33^{\circ} 28^{\prime} 12.1^{\prime \prime} \mathrm{N}, 108^{\circ} 29^{\prime} 26.2^{\prime \prime} \mathrm{E}\right)$ in July and August 2019. The logs were transported to the Huoditang Forest Farm experiment base, placed in a greenhouse, covered by a thin stainless-steel net (bore diameter $\leq 0.8 \mathrm{~mm}$ ) and watered to keep the bark moist. Once emerging beetles appeared in the net, active beetles were collected and analysed on the same day using toxicity assays (Light, 1983; Zhang et al., 2006).

\section{Chemicals}

The chemicals used in this study are listed in Table 1.

Table 1. The purity of host volatiles and companies (with addresses) from which these chemicals were purchased

\begin{tabular}{c|c|c|c}
\hline Volatile & Purity & Company & Address \\
\hline (-)- $\alpha$-Pinene & $\geq 99.0 \%$ & sigma & Shanghai, China \\
$(+)-\alpha$-Pinene & Analytical standard & sigma & Shanghai, China \\
$(-)-\beta$-Pinene & Analytical standard & sigma & Shanghai, China \\
$(+)-\beta$-Pinene & Analytical standard & sigma & Shanghai, China \\
Myrcene & $\geq 99.0 \%$ & Yuanye Bio-Technology Co., Ltd & Shanghai, China \\
$S$-(-)-limonene & Analytical standard & sigma & Shanghai, China \\
$R$-(+)-limonene & Analytical standard & sigma & Shanghai, China \\
$(+)-3$-carene & Analytical standard & sigma & Shanghai, China \\
$(+)-$ longifolene & $\geq 99.0 \%$ & Yuanye Bio-Technology Co., Ltd & Shanghai, China \\
\hline
\end{tabular}

\section{Toxicity assays}

Certain volatiles from the GC-MS analysis of $P$. armandii phloem were chosen for toxicity assays (Table 1). Camphene was in a solid state at room temperature and was not chosen for the toxicity assays. The toxic effects of trans-verbenol, verbenone, myrtenol, and myrtenal on D. armandii have previously been explored (Zhao et al., 2017b, 2019) 
and were not examined in this study. The toxicity of (-)- $\alpha$-Pinene, $(+)-\alpha-$-pinene, $(-)-\beta-$ pinene, (+)- $\beta$-pinene, myrcene, $S$-(-)-limonene, $R$-(+)-limonene, $(+)-3$-carene and $(+)-$ longifolene towards $D$. armandii was tested using a method used previously for $D$. ponderosae (Reid et al., 2017; Chiu et al., 2017). A $1.5 \times 1.5 \mathrm{~cm}$ filter paper was placed in a $20 \mathrm{~mL}$ glass vial as the reagent carrier. Different dosages of the test volatiles were applied to the filter paper using a micro-dispenser. Beetles in the control group were exposed to untreated filter paper for $24 \mathrm{~h}$. Each glass vial contained only one D. armandii, and the glass vials were sealed after the beetles were placed inside. Before the beetle was put into the glass bottle, they were weighed. Preliminary toxicity tests were conducted with each volatile to refine an intermediate range of dosages from lethal to non-lethal, to more accurately determine an $\mathrm{LC}_{50}$ (Table 2). The $D$. armandii beetles were maintained in glass vials for $24 \mathrm{~h}$. After that, $D$. armandii were considered to have died if they showed no limb movements after the glass vial was shaken. Each $D$. armandii was weighed again to calculate their weight loss. Each concentration (contain all concentration in the preliminary experiments and the experiments of $\mathrm{LC}_{50}$ ) of each tested volatile compound was tested with $40 \mathrm{D}$. armandii individuals (20 females and 20 males). To eliminate potential bias of different treatment in results, beetles collected at different times were used for all the assays in a completely random manner.

Table 2. The determination doses of different volatiles for females and males

\begin{tabular}{|c|c|c|c|c|c|c|c|c|c|c|c|}
\hline \multirow{2}{*}{ Volatile } & \multirow{2}{*}{ Sex } & \multicolumn{10}{|c|}{ Volatile dosage $(\mu \mathrm{L})$} \\
\hline & & $\mathbf{0}$ & 0.2 & 0.4 & 0.7 & 1 & 1.5 & 2 & 4 & 10 & 15 \\
\hline \multirow{2}{*}{ (-)- $\alpha$-Pinene } & Male & $\sqrt{ }$ & & $\sqrt{ }$ & & $\sqrt{ }$ & $\sqrt{ }$ & $\sqrt{ }$ & & & \\
\hline & Female & $\sqrt{ }$ & & $\sqrt{ }$ & & $\sqrt{ }$ & $\sqrt{ }$ & $\sqrt{ }$ & & & \\
\hline \multirow{2}{*}{$(+)$ - $\alpha$-Pinene } & Male & $\sqrt{ }$ & & $\sqrt{ }$ & $\sqrt{ }$ & $\sqrt{ }$ & & $\sqrt{ }$ & & & \\
\hline & Female & $\sqrt{ }$ & & & $\sqrt{ }$ & $\sqrt{ }$ & $\sqrt{ }$ & $\sqrt{ }$ & & & \\
\hline \multirow{2}{*}{ (-)- $\beta$-Pinene } & Male & $\sqrt{ }$ & & $\sqrt{ }$ & & $\sqrt{ }$ & $\sqrt{ }$ & $\sqrt{ }$ & & & \\
\hline & Female & $\sqrt{ }$ & & $\sqrt{ }$ & & $\sqrt{ }$ & $\sqrt{ }$ & $\sqrt{ }$ & & & \\
\hline \multirow{2}{*}{$(+)-\beta$-Pinene } & Male & $\sqrt{ }$ & & $\sqrt{ }$ & & $\sqrt{ }$ & $\sqrt{ }$ & $\sqrt{ }$ & & & \\
\hline & Female & $\sqrt{ }$ & & $\sqrt{ }$ & & $\sqrt{ }$ & $\sqrt{ }$ & $\sqrt{ }$ & & & \\
\hline \multirow{2}{*}{ Myrcene } & Male & $\sqrt{ }$ & & & & & & $\sqrt{ }$ & $\sqrt{ }$ & $\sqrt{ }$ & $\sqrt{ }$ \\
\hline & Female & $\sqrt{ }$ & & & & 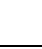 & & $\sqrt{ }$ & $\sqrt{ }$ & $\sqrt{ }$ & $\sqrt{ }$ \\
\hline \multirow{2}{*}{$S$-(-)-limonene } & Male & $\sqrt{ }$ & & $\sqrt{ }$ & $\sqrt{ }$ & $\sqrt{ }$ & & $\sqrt{ }$ & & & \\
\hline & Female & $\sqrt{ }$ & & $\sqrt{ }$ & $\sqrt{ }$ & $\sqrt{ }$ & & $\sqrt{ }$ & & & \\
\hline \multirow{2}{*}{$R$-(+)-limonene } & Male & $\sqrt{ }$ & $\sqrt{ }$ & $\sqrt{ }$ & & $\sqrt{ }$ & & $\sqrt{ }$ & & & \\
\hline & Female & $\sqrt{ }$ & & $\sqrt{ }$ & $\sqrt{ }$ & $\sqrt{ }$ & & $\sqrt{ }$ & & & \\
\hline \multirow{2}{*}{$(+)$-3-carene } & Male & $\sqrt{ }$ & & $\sqrt{ }$ & $\sqrt{ }$ & $\sqrt{ }$ & & $\sqrt{ }$ & & & \\
\hline & Female & $\sqrt{ }$ & & $\sqrt{ }$ & $\sqrt{ }$ & $\sqrt{ }$ & & $\sqrt{ }$ & & & \\
\hline \multirow{2}{*}{ (+)-longifolene } & Male & $\sqrt{ }$ & & & & & & $\sqrt{ }$ & $\sqrt{ }$ & $\sqrt{ }$ & $\sqrt{ }$ \\
\hline & Female & $\sqrt{ }$ & & & & & & $\sqrt{ }$ & $\sqrt{ }$ & $\sqrt{ }$ & $\sqrt{ }$ \\
\hline
\end{tabular}

\section{Statistical analysis}

The probit analysis method was used to determine the $\mathrm{LC}_{50}$. One-way ANOVA was used to test for differences in the mean weights of males and females. Multiple comparisons (LSD- $t$ test) were used to test the difference in mean \% of limonene, mean weight loss, mean weight loss $\%$ and death rate $\%$. The probit analysis, one-way ANOVA and multiple comparisons $(P<0.05)$ were run in SPSS (1999). 


$$
-592-
$$

\section{Results}

\section{Collection and identification of host volatiles}

In the GC-MS analysis of the phloem during four different $P$. armandii periods (healthy period, resistance period, retreat period and withered period), eleven host volatiles were detected (Table 3). Eight host volatiles ( $\alpha$-pinene, camphene, $\beta$-pinene, myrcene, 3-carene, myrtenol, verbenone, longifolene) were detected in all four periods. trans-Verbenol was only detected in the resistance period, and myrtanol was only detected in the retreat period. The percentage of limonene in the total phloem volatiles was similar during the healthy and retreat periods, significantly increased during the resistance period, and absent in the withered period (Fig. 1). Over thirty volatiles (accounting for 18\%-30\%), including pentadecane, naphthalene, tetradecane, octadecane, and acenaphthene, were also detected. Because theses volatiles were not major volatiles (such as $\alpha$-pinene) or were not markedly changed in the different periods (such as myrtanol) in the preliminary analysis, they were not subjected to further analysis.

Table 3. Mean (SE) percentage composition of identified volatiles emitted from phloem of Pinus armandii during different stages of infestation by Dendroctonus armandii. Five replicate samples were analysed for each period

\begin{tabular}{c|c|c|c|c}
\hline & $\begin{array}{c}\text { Healthy period } \\
(\mathbf{n = 5})\end{array}$ & $\begin{array}{c}\text { Resistance period } \\
(\mathbf{n = 5})\end{array}$ & $\begin{array}{c}\text { Retreat period } \\
(\mathbf{n = 5})\end{array}$ & $\begin{array}{c}\text { Withered period } \\
(\mathbf{n = 5})\end{array}$ \\
\hline$\alpha$-Pinene & $77.46 \pm 3.72(5)$ & $65.69 \pm 24.71(5)$ & $61.41 \pm 11.34(5)$ & $60.07 \pm 9.41(5)$ \\
Camphene & $1.74 \pm 0.92(5)$ & $1.45 \pm 0.77(5)$ & $10.72 \pm 5.79(5)$ & $21.31 \pm 18.75(3)$ \\
$\beta$-pinene & $5.10 \pm 0.56(5)$ & $11.42 \pm 7.23(5)$ & $13.35 \pm 4.65(5)$ & $11.99 \pm 6.81(5)$ \\
Myrcene & $5.44 \pm 1.23(5)$ & $5.17 \pm 3.30(5)$ & $2.1 \pm 1.47(5)$ & $8.06 \pm 3.13(4)$ \\
Limonene & $8.81 \pm 2.65(5)$ & $15.08 \pm 5.53(5)$ & $9.24 \pm 4.22(5)$ & $\mathrm{ND}^{\mathrm{b}}$ \\
3-Carene & $1.75 \pm 1.61(5)$ & $0.09 \pm 0.02(5)$ & $0.8 \pm 0.74(5)$ & $5.12 \pm 4.16$ \\
trans-Verbenol & $\mathrm{ND}^{\mathrm{b}}$ & $0.01 \pm 0.01(5)$ & $\mathrm{ND}^{\mathrm{b}}$ & $\mathrm{ND}^{\mathrm{b}}$ \\
Myrtenol & $0.025 \pm 0.015(2)$ & $0.02(1)$ & $0.13 \pm 0.11(2)$ & $0.017(1)$ \\
verbenone & $0.028 \pm 0.011(5)$ & $0.03 \pm 0.02(5)$ & $0.14 \pm 0.13(5)$ & $0.044 \pm 0.027(4)$ \\
Myrtanol & $\mathrm{ND}^{\mathrm{b}}$ & $\mathrm{ND}^{\mathrm{b}}$ & $0.04 \pm 0.03(3)$ & $\mathrm{ND}^{\mathrm{b}}$ \\
Longifolene & $1.38 \pm 0.72(5)$ & $1.05 \pm 1.02(5)$ & $2.18 \pm 1.02(5)$ & $1.17 \pm 0.69(5)$ \\
\hline
\end{tabular}

${ }^{a}$ The values shown are the means $\pm \mathrm{SE}$, and the values in parentheses are the number of samples in which the component was identified

${ }^{b} \mathrm{ND}$ indicates that the pheromone was not detected

\section{Toxicity assays}

The mean weight (+/-SE) of female $D$. armandii $(9.74+/-0.05)$ was marginally but significantly higher than that of males $(9.17+/$ - 0.05) (ANOVA, $F=60.39$, df $=1798$, $P<0.01)$. After the toxicity assays, each beetle was re-weighed and the percentage weight loss was calculated. There was a significant difference between the experiment group and the control group, the beetles exposed to host volatiles lost more mass than control beetles (Fig. 2). Although there was no significant difference between experiment females and males, the females lost more mass than males (Fig. 2). Males 
$(14.14+/-0.33)$ lost a higher percentage of weight than females $(13.80+/-0.33)$, but the difference was not significant (LSD- $t, P=0.467$ ). After $24 \mathrm{~h}$ of volatile treatment, the death rate was calculated for the experiment and control groups. The death rate of experiment males was significantly higher than that of control males, the death rate of experiment females was significantly higher than that of control females (Fig. 3). There was a significant difference between experiment females and experiment males, and the experiment males had a higher death rate than females (Fig. 3).

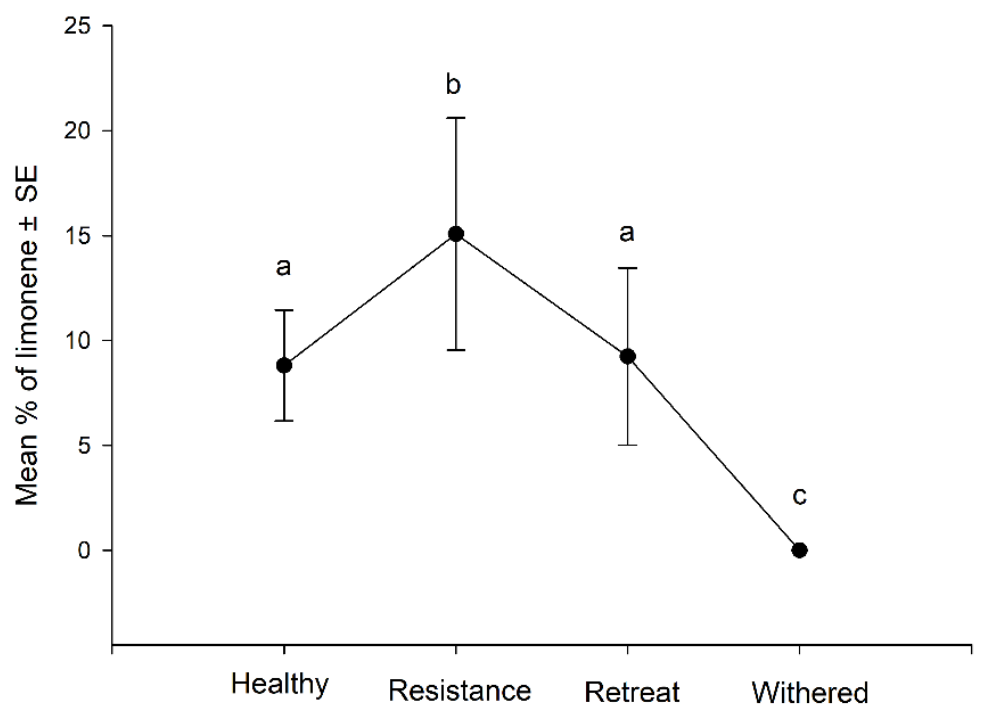

Figure 1. Mean $\% \pm S E$ of limonene in four P. armandii periods. Different letters indicate a significant difference (LSD; $p<0.01)$, and the same letter indicates no significant difference

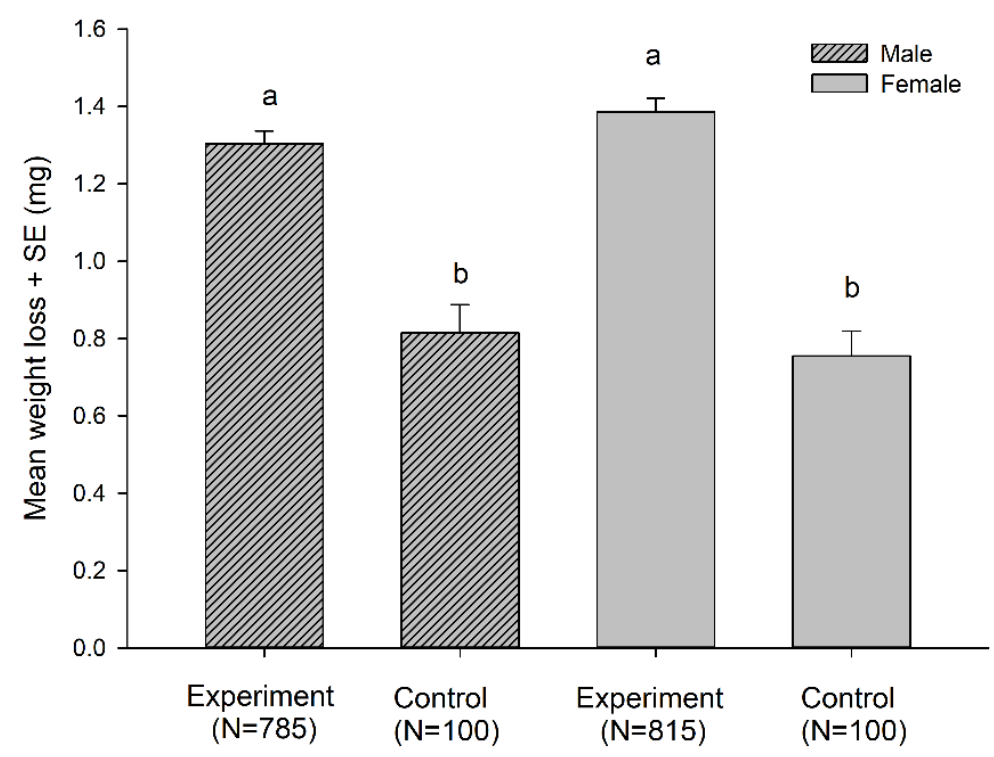

Figure 2. Mean weight loss $+S E(m g)$ of D. armandii males and females after 24 h exposure to various phloem volatiles on filter paper (experimental group) or untreated filter paper (control group). Means with different letters differed significantly $(L S D, P<0.01)$. Numbers in parentheses are the numbers of beetles measured 


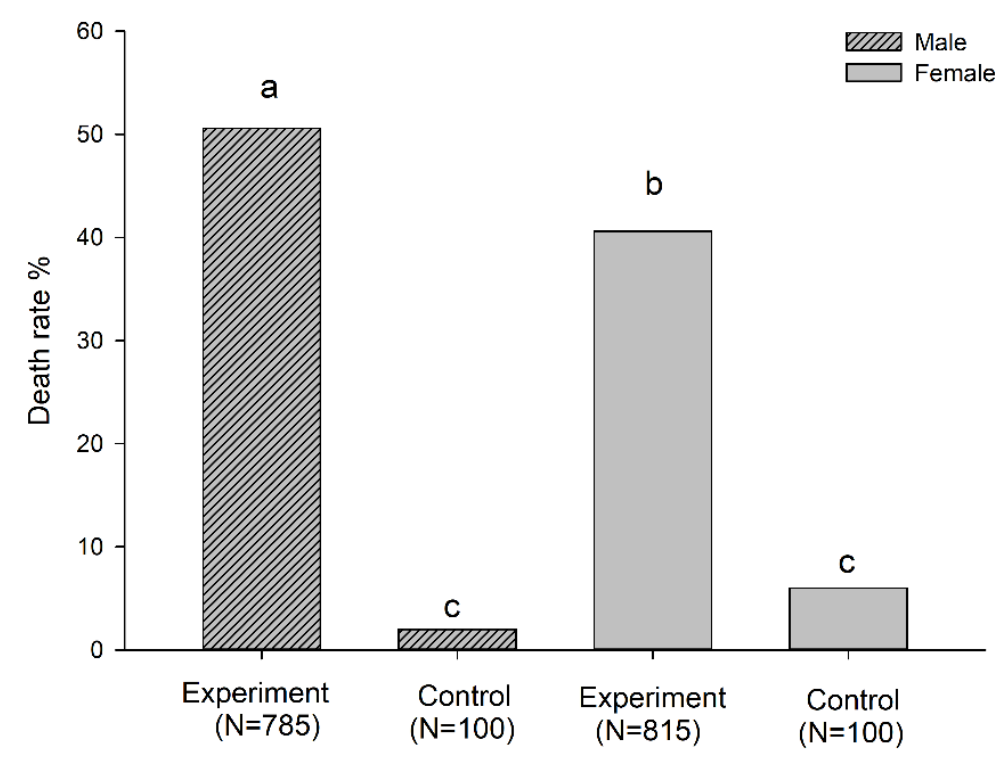

Figure 3. Percentage mortality of D. armandii exposed for 24 h to various dosages of phloem volatiles on filter paper (experimental group) or untreated filter paper (control group).

Percentage mortality with different letters differed significantly $(L S D, P<0.01)$. Numbers in parentheses are the numbers of beetles measured

The $\mathrm{LC}_{50}$ values for nine host volatiles at $24 \mathrm{~h}$ of vapour exposure to $D$. armandii were measured. The range of $\mathrm{LC}_{50}$ values was from 17 to $>750$, revealing the differences in toxicity of different host volatiles (Table 4$). R$-(+)-Limonene was the most toxic host volatile to both females and males, followed by (+)-3-carene and $S$-(-)limonene. This ranking was consistent in females and males. The next most toxic volatiles were $(+)$ and (-) of $\alpha$-pinene and $(+)$ and $(-)$ of $\beta$-pinene. Myrcene and $(+)-$ longifolene were the two lowest toxicity host volatiles. $R$-(+)-Limonene, $(+)-3$-carene, $S$-(-)-limonene, (-)- $\alpha$-pinene, $(+)$ - $\alpha$-pinene, $(+)-\beta$-pinene and myrcene were more toxic to males than to females. (-)- $\beta$-Pinene and (+)-longifolene were more toxic to females than to males (Table 4).

Table 4. The lethal concentration of elect phloem volatiles necessary to kill $50 \%$ of D. armandii males and females after $24 \mathrm{~h}$ exposure

\begin{tabular}{c|c|c|c}
\hline \multicolumn{2}{c|}{ Male } & \multicolumn{2}{|c}{ Female } \\
\hline Volatile & $\mathrm{LC}_{50}(\mu \mathrm{L} / \mathrm{L})$ & Volatile & $\mathrm{LC}_{50}(\mu \mathrm{L} / \mathrm{L})$ \\
$R$-(+)-limonene & 17 & $R$-(+)-limonene & 32 \\
(+)-3-carene & 25 & $(+)-3$-carene & 39 \\
$S$-(-)-limonene & 42 & $S$-(-)-limonene & 49 \\
$(-)-\alpha$-Pinene & 60 & $(+)-\alpha$-Pinene & 68 \\
$(+)-\alpha$-Pinene & 61 & $(-)-\beta$-Pinene & 70 \\
$(+)-\beta$-Pinene & 62 & $(+)-\beta$-Pinene & 74 \\
(-)- $\beta$-Pinene & 73 & $(-)$ - $\alpha$-Pinene & 82 \\
Myrcene & 399 & Myrcene & 507 \\
(+)-longifolene & $>750$ & $(+)$-longifolene & 682 \\
\hline
\end{tabular}

The probit analysis method was used to determine the $\mathrm{LC}_{50}$ in SPSS (1999). Less than $50 \%$ of the males died at all test doses of (+)-longifolene 


\section{Discussion}

Female D. armandii are responsible for locating and invading hosts, overcoming tree defence, building tunnels and oviposition, and males are mainly responsible for mating. Comparison of the body weights of male and female individuals revealed that the mean weight of female $D$. armandii was significantly higher than that of males. This is in line with their respective roles. Females take on more work and need more energy. After exposure to host volatiles, the weight loss (absolute values and percentages) of both sexes were significantly different between the experiment and control groups (Fig. 2). This demonstrated that the host volatiles have significant toxicity to female and male $D$. armandii. The death rate in the beetles exposed to host volatiles was significantly higher in males than in females, indicating that females are more resistant to the toxic effects of the tested pine volatiles. The $\mathrm{LC}_{50}$ values for $24 \mathrm{~h}$ of exposure to each tested host volatile except (+)-longifolene were higher in females than in males, further indicating that females are more resistant to the toxic effects of pine volatiles than males. Toxicity is usually affected by an individual organism's weight, and females were significantly larger than males; this could at least partially explain why the $\mathrm{LC}_{50}$ s for females were higher than those for males.

In previous research with $D$. ponderosae, beetle gender had no significant effects on body weight or toxicity of most monoterpenes (Chiu et al., 2017; Reid et al., 2017). A possible reason for the difference may be because at low population densities, $D$. ponderosae colonizes weakened pine and colonizes and kills healthy pine trees when beetle populations are at high densities (Krause et al., 2018; Coops et al., 2008). Whereas $D$. armandii mainly invades healthy pine greater than 30 years old (Chen et al., 2010). Due to the differences in the health status of these hosts, it can be concluded that female $D$. armandii consume more energy than female $D$. ponderosae to resist host pine resistance during invasion. At the same time, female $D$. armandii need stronger antihost defence abilities than female $D$. ponderosae to ensure successful invasion. Female $D$. armandii have evolved significant differences from male $D$. armandii. In $D$. valens, the host defence chemicals, mainly volatile $\alpha$-pinene, were found to influence its feeding behaviour and gut bacterial community structure (Xu et al., 2016). In other Dendroctonus spp. (Dendroctonus rhizophagus, D. brevicomis, D. frontalis, Dendroctonus rufipennis), although the host volatiles were identified and applied in behavioural research (Cano-Ramírez et al., 2012; Sullivan, 2005; Ryall et al., 2013), the toxicity of the host volatiles was not determined.

Pinus contorta and Pinus banksiana are hosts of D. ponderosae. Limonene was detected as one of the main volatiles in P. contorta and P. banksiana, accounting for $5.26 \pm 0.85 \%$ and $4.77 \pm 0.99 \%$ of the total volatiles (Clark et al., 2014). The toxicity of (-)-limonene to $D$. ponderosae was the strongest among a few test host volatiles, including ((-)- $\beta$-phellandrene, (+)-3-carene, myrcene, terpinolene, (-)- $\alpha$-pinene, $(+)-\alpha-$ pinene, (-)- $\beta$-pinene, (+)- $\beta$-pinene, (-)-limonene and (+)-limonene), and (+)-limonene was the second most toxic (Chiu et al., 2017). The $\mathrm{LC}_{50}$ of (-)-limonene and (+)limonene were 49 and $89 \mu \mathrm{L} / \mathrm{L}$, respectively, for $D$. ponderosae. Compared with our research results (Tables 3 and 4 ), the percentage of limonene in healthy P. armandii was higher than in $P$. contorta and $P$. banksiana; at the same time, the $\mathrm{LC}_{50}$ of limonene was lower in $D$. armandii than in $D$. ponderosae. These results show that $P$. armandii has advantages in resisting bark beetle invasion compared with $P$. contorta and $P$. banksiana. Although limonene was not detected in more host survival states, limonene was the main volatile in the $D$. ponderosae host and was the most toxic host volatile. 
The percentage dosage may increase in the host resistance period and increase host defence. However, this still needs further research. Limonene was also the main volatile found in Picea abies (the host of Ips typographus) (Persson et al., 1996), Pinus tabuliformis (the host of $D$. valens) (Chen et al., 2019), and Pinus ponderosa (the host of $D$. brevicomis) (Kolb et al., 2019). Adding limonene to the standard lure ([1:1:1 blend of (+)-alpha-pinene, (-)-beta-pinene, and (+)-3-carene]) decreased the response of D. valens but not significantly (Sun et al., 2004). While the toxicity and the existential state of limonene were not further considered in these studies, if limonene was the main host defence against invasion of Dendroctonus spp., more related data is needed for other bark beetle species.

Myrtenol was present in very low amounts $(<0.2 \%)$ during all periods of $P$. armandii invasion by $D$. armandii colonization (Table 3). (1R)-myrtenol was converted into both (1R)-myrtenal and (1R)-myrtanol using a $P$. abies suspension culture (Lindmark-Henriksson et al., 2004). Based on the research result, myrtenol may be the raw material of myrtanol in the retreat period of $P$. armandii. In our previous study, myrtanol was found to be toxic to $D$. armandii, especially females (Zhao et al., 2019). Myrtanol was produced in the retreat period of $P$. armandii; at this time, the resin flow stopped, and females released pheromones to attract males for mating. At the same time, the females were the most numerous sex, the number of males gradually increased. The toxicity of the generated myrtanol was stronger in females than in males (Zhao et al., 2019), this was consistent with the bark beetle population proportion in the retreat period of $P$. armandii.

Based on these studies, the chemical defence of $P$. armandii has gradually become clear. After the first female $D$. armandii tunnels into the $P$. armandii trunk, the tree responds with host defences (the resistance period). Two lines of defence in the $P$. armandii phloem were launched to resist the invasion of $D$. armandii. At first, $P$. armandii secreted resin to mount a physical attack on D. armandii. The concentration of host phloem volatiles was increased (Kolb et al., 2019), and at the same time, the \% dosage of the key volatile limonene in the phloem rapidly increased, leading to $D$. armandii death. If the first defensive line was overcome, $P$. armandii entered the retreat period. The resin production was hindered by L. qinlingensis, and the $\%$ dosage of limonene was lowered. At this time, the second defensive line was initiated. P. armandii used volatiles (perhaps myrtenol) to synthesize the toxic compound myrtanol to resist $D$. armandii, especially females. If the second defensive line was overcome by $D$. armandii, limonene and myrtanol became absent in the phloem. $P$. armandii then entered the withered period and was unable to resist invasion.

\section{Conclusion}

In summary, this research provided evidence that females were stronger and were significantly better than males at resisting the toxicity of host volatiles. The differences between $D$. armandii and other Dendroctonus spp. shows that distinct bark beetle management must be used for the former. During the $D$. armandii invasion process, $P$. armandii phloem organized two defensive lines to resist the invasion of $D$. armandii. Furthermore, our results indicated that the percentage of limonene was elevated from the healthy period to the resistance period and decreased from the resistance period to the retreat period, while limonene was absent in the withered period. What triggers these changes in limonene is still not clear. Myrtanol was produced in the retreat period 
and disappeared in the withered period. Myrtanol was produced after the first line of defence was broken, but the factors that resulted in its disappearance are not clear. Further research is needed to determine the biosynthetic mechanisms of limonene and myrtanol in $P$. armandii. Furthermore, whether limonene and myrtanol were toxic to the fungi carried by $D$. armandii was not clear. The defence of $P$. armandii against fungi is also worthy of further study.

Acknowledgements. This research was funded by the National Natural Science Foundation of China (31870636) and the National Key Research and Development Program of China (2017YFD0600104).

\section{REFERENCES}

[1] Arango-Velez, A., El Kayal, W., Copeland, C. C. J., Zaharia, L. I., Lusebrink, I., Cooke, J. E. K. (2016): Differences in defence responses of Pinus contorta and Pinus banksiana to the mountain pine beetle fungal associate Grosmannia clavigera are affected by water deficit. - Plant Cell and Environment 39: 726-744.

[2] Arango-Velez, A., Chakraborty, S., Blascyk, K., Phan, M. T., Barsky, J., El Kayal, W. (2018): Anatomical and chemical responses of eastern white pine (Pinus strobus L.) to blue-stain (Ophiostoma minus) inoculation. - Forests 9: 690.

[3] Blazenec, M., Jakus, R. (2009): Effect of (+)-limonene and 1-methoxy-2-propanol on Ips typographus response to pheromone blends. - Journal of Forest Research 20: 37-44.

[4] Byers, J. A., Wood, D. L., Craig, J., Hendry, L. B. (1984): Attractive and inhibitory pheromones produced in the bark beetle, Dendroctonus brevicomis, during host colonization: regulation of inter- and intraspecific competition. - Journal of Chemical Ecology 10: 861-877.

[5] Cano-Ramírez, C., Armendáriz-Toledano, F., Macías-Sámano, J. E., Sullivan, B. T., Zúñiga, G. (2012): Electrophysiological and behavioral responses of the bark beetle Dendroctonus rhizophagus to volatiles from host pines and conspecifics. - Journal of Chemical Ecology 38: 512-524.

[6] Chai, Q. Q., Wu, B. H., Liu, W. S., Wang, L. J., Yang, C. X., Wang, Y. J. et al. (2012): Volatiles of plums evaluated by HS-SPME with GC-MS at the germplasm level. - Food Chemistry 130: 432-440.

[7] Chen, H., Tang, M. (2007): Spatial and temporal dynamics of bark beetles in Chinese white pine in Qinling Mountains of Shaanxi Province, China. - Environmental Entomology 36: 1124-1130.

[8] Chen, H., Li, Z., Tang, M. (2010): Laboratory evaluation of flight activity of Dendroctonus armandi (Coleoptera: Curculionidae: Scolytinae). - Canadian Entomologist 142: 378-387.

[9] Chen, G. F., Song, Y. S., Wang, P. X., Chen, J. Y., Zhang, Z., Wang, S. M. et al. (2015): Semiochemistry of Dendroctonus armandii Tsai and Li (Coleoptera: Curculionidae: Scolytinae): both female-produced aggregation pheromone and host tree kairomone are critically important. - Chemoecology 25: 135-145.

[10] Chen, J. G., Bi, H. X., Yu, X. X., Fu, Y. L., Liao, W. C. (2019): Influence of physiological and environmental factors on the diurnal variation in emissions of biogenic volatile compounds from Pinus tabuliformis. - Journal of Environmental Sciences 81: $102-118$

[11] Chiu, C. C., Keeling, C. I., Bohlmann, J. (2017): Toxicity of pine monoterpenes to Mountain Pine Beetle. - Scientific Reports 7: 8858.

[12] Chiu, C. C., Keeling, C. I., Bohlmann, J. (2018): Monoterpenyl esters in juvenile mountain pine beetle and sex-specific release of the aggregation pheromone transverbenol. - PNAS 115: 3652-3657. 
[13] Clark, E. L., Pitt, C., Carroll, A. L., Lindgren, B. S., Huber, D. P. W. (2014): Comparison of lodgepole and jack pine resin chemistry: implications for range expansion by the mountain pine beetle Dendroctonus ponderosae (Coleoptera: Curculionidae). - PeerJ 2: 240.

[14] Coops, N. C., Timko, J. A., Wulder, M. A., White, J. C., Ortlepp, S. M. (2008): Investigating the effectiveness of mountain pine beetle mitigation strategies. International Journal of Pest Management 54: 151-165.

[15] Dai, L. L., Ma, M. Y., Wang, C. Y., Shi, Q., Zhang, R. R., Chen, H. (2015): Cytochrome P450s from the Chinese white pine beetle, Dendroctonus armandi (Curculionidae: Scolytinae): Expression profiles of different stages and responses to host allelochemicals. - Insect Biochemistry and Molecular Biology 65: 35-46.

[16] Erbilgin, N., Cale, J. A., Lusebrink, I., Najar, A., Klutsch, J. G., Sherwood, P. et al. (2017): Water-deficit and fungal infection can differentially affect the production of different classes of defense compounds in two host pines of mountain pine beetle. - Tree Physiology 37: 338-350.

[17] Faccoli, M., Stergulc, F. (2008): Damage reduction and performance of mass trapping devices for forest protection against the spruce bark beetle, Ips typographus (Coleoptera Curculionidae Scolytinae). - Annals of Forest Science 65: 309.

[18] Franceschi, V. R., Krokene, P., Christiansen, E., Krekling, T. (2005): Anatomical and chemical defenses of conifer bark against bark beetles and other pests. - New Phytologist 167: 353-375.

[19] Gillette, N. E., Stein, J. D., Owen, D. A., Webster, J. N., Fiddler, G. O., Mori, S. R. et al. (2006): Verbenone-releasing flakes protect individual Pinus contorta trees from attack by Dendroctonus ponderosae and Dendroctonus valens (Coleoptera: Curculionidae, Scolytinae). - Agricultural and Forest Entomology 8: 243-251.

[20] Gillette, N. E., Erbilgin, N., Webster, J. N., Pederson, L., Mori, S. R., Stein, J. D. et al. (2009): Aerially applied verbenone-releasing laminated flakes protect Pinus contorta stands from attack by Dendroctonus ponderosae in California and Idaho. - Forest Ecology and Management 257: 1405-1412.

[21] Hood, S., Sala, A. (2015): Ponderosa pine resin defenses and growth: metrics matter. Tree Physiology 35: 1223-1235.

[22] Hu, X., Li, M., Zhang, F. P., Chen, H. (2016): Influence of starvation on the structure of gut-associated bacterial communities in the Chinese white pine beetle (Dendroctonus armandi). - Forests 7: 126.

[23] Kane, J. M., Kolb, T. E. (2010): Importance of resin ducts in reducing ponderosa pine mortality from bark beetle attack. - Oecologia 164: 601-609.

[24] Keenan, D. F., Brunton, N. P., Mitchell, M., Gormley, R., Butler, F. (2012): Flavour profiling of fresh and processed fruit smoothies by instrumental and sensory analysis. Food Research International 45: 17-25.

[25] Kolb, T., Keefover-Ring, K., Burr, S. J., Hofstetter, R., Gaylord, M., Raffa, K. F. (2019): Drought-mediated changes in tree physiological processes weaken tree defenses to bark beetle attack. - Journal of Chemical Ecology 45: 888-900.

[26] Krause, A. M., Townsend, P. A., Lee, Y., Raffa, K. F. (2018): Predators and competitors of the mountain pine beetle Dendroctonus ponderosae (Coleoptera: Curculionidae) in stands of changing forest composition associated with elevation. - Agricultural and Forest Entomology 20: 402-413.

[27] Li, X. J., Gao, J. M., Chen, H., Zhang, A. L., Tang, M. (2012): Toxins from a symbiotic fungus, Leptographium qinlingensis associated with Dendroctonus armandi and their in vitro toxicities to Pinus armandi seedlings. - European Journal of Plant Pathology 134: 239-247.

[28] Light, D. M. (1983): Sensitivity of antennae of male and female Ips paraconfusus (Coleoptera: Scolytidae) to its pheromone and other behavior-modifying chemicals. Journal of Chemical Ecology 9: 585-606. 
[29] Lindmark-Henriksson, M., Isaksson, D., Vaněk, T., Valterová, I., Högberg, H. E., Sjödin, K. (2004): Transformation of terpenes using a Picea abies suspension culture. - Journal of Biotechnology 107: 173-184.

[30] Persson, M., Sjödin, K., Borg-Karlson, A. K., Norin, T., Ekberg, I. (1996): Relative amounts and enantiomeric compositions of monoterpene hydrocarbons in xylem and needles of Picea abies. - Phytochemistry 42: 1289-1297.

[31] Ning, H., Dai, L. L., Fu, D. Y., Liu, B., Wang, H. L., Chen, H. (2019): Factors influencing the geographical distribution of Dendroctonus armandi (Coleoptera: Curculionidae: Scolytidae) in China. - Forests 10: 425.

[32] Perkins, D. L., Jorgensen, C. L., Rinella, M. J. (2015): Verbenone decreases whitebark pine mortality throughout a Mountain Pine Beetle outbreak. - Forest Science 61: 747752.

[33] Pureswaran, D. S., Borden, J. H. (2004): New repellent semiochemicals for three species of Dendroctonus (Coleoptera: Scolytidae). - Chemoecology 14: 67-75.

[34] Pureswaran, D. S., Hofstetter, R. W., Sullivan, B. T. (2008): Attraction of the southern pine beetle, Dendroctonus firontalis, to pheromone components of the western pine beetle, Dendroctonus brevicomis (Coleoptera: Curculionidae: Scolytinae), in an allopatric zone. - Environmental Entomology 37: 70-78.

[35] Raffa, K. F., Mason, C. J., Bonello, P., Cook, S., Erbilgin, N., Keefover-Ring, K. et al. (2017): Defence syndromes in lodgepole - whitebark pine ecosystems relate to degree of historical exposure to mountain pine beetles. - Plant Cell and Environment 40: 17911806.

[36] Reid, M. L., Sekhon, J. K., LaFramboise, L. M. (2017): Toxicity of monoterpene structure, diversity and concentration to Mountain Pine Beetles, Dendroctonus ponderosae: beetle traits matter more. - Journal of Chemical Ecology 43: 351-361.

[37] Roth, M., Hussain, A., Cale, J. A., Erbilgin, N. (2018): Successful colonization of lodgepole pine trees by mountain pine beetle increased monoterpene production and exhausted carbohydrate reserves. - Journal of Chemical Ecology 44: 209-214.

[38] Ryall, K. L., Silk, P., Thurston, G. S., Scarr, T. A., de Groot, P. (2013): Elucidating pheromone and host volatile components attractive to the spruce beetle, Dendroctonus rufipennis (Coleoptera: Curculionidae), in eastern Canada. - Canadian Entomologist 145: 406-415.

[39] Strom, B. L., Goyer, R. A., Ingram, L. L., Boyd, G. D. L., Lott, L. H. (2002): Oleoresin characteristics of progeny of loblolly pines that escaped attack by the southern pine beetle. - Forest Ecology and Management 158: 169-178.

[40] Sullivan, B. T. (2005): Electrophysiological and behavioral responses of Dendroctonus frontalis (Coleoptera: Curculionidae) to volatiles isolated from conspecifics. - Journal of Economic Entomology 98: 2067-2078.

[41] Sun, J. H., Miao, Z. W., Zhang, Z., Zhang, Z. N., Gillette, N. E. (2004): Red turpentine beetle, Dendroctonus valens LeConte (Coleoptera: Scolytidae), response to host semiochemicals in China. - Environmental Entomology 33: 206-212.

[42] Sun, J. H., Lu, M., Gillette, N. E., Wingfield, M. J. (2013): Red Turpentine Beetle: innocuous native becomes invasive tree killer in China. - Annual Review of Entomology 58: 293-311.

[43] Xie, S. A., Lv, S. J. (2012): An improved lure for trapping the bark beetle Dendroctonus armandi (Coleoptera: Scolytinae). - European Journal of Entomology 109: 569-577.

[44] Xu, L. T., Shi, Z. H., Wang, B., Lu, M., Sun, J. H. (2016): Pine defensive monoterpene $\alpha-$ pinene influences the feeding behavior of Dendroctonus valens and its gut bacterial community structure. - International Journal of Molecular Sciences 17: 1734.

[45] Zhang, L. W., Sun, J. H., Clarke, S. R. (2006): Effects of verbenone dose and enantiomer on the interruption of response of the red turpentine beetle, Dendroctonus valens LeConte (Coleoptera: Scolytidae), to its kariomones. - Environmental Entomology 35: 655-660. 
[46] Zhao, M. Z., Dai, L. L., Fu, D. Y., Gao, J., Chen, H. (2017a): Electrophysiological and behavioral responses of Dendroctonus armandi (Coleoptera: Curculionidae: Scolytinae) to two candidate pheromone components: frontalin and exo-brevicomin. - Chemoecology 27: 91-99.

[47] Zhao, M. Z., Dai, L. L., Sun, Y. Y., Fu, D. Y., Chen, H. (2017b): The pheromone verbenone and its function in Dendroctonus armandi (Coleoptera: Curculionidae: Scolytinae). - European Journal of Entomology 114: 53-60.

[48] Zhao, M. Z., Liu, B., Sun, Y. Y., Wang, Y. Y., Dai, L. L., Chen, H. (2019): Presence and roles of myrtenol, myrtanol and myrtenal in Dendroctonus armandi (Coleoptera: Curculionidae: Scolytinae) and Pinus armandi (Pinales: Pinaceae: Pinoideae). - Pest Management Science 76: 188-197. 